\title{
New Genetic Lineage of Tula Hantavirus in Microtus arvalis obscurus in Eastern Kazakhstan
}

\author{
Angelina Plyusnina ${ }^{1}$, Juha Laakkonen ${ }^{2, \S}$, Jukka Niemimaa ${ }^{2}$, Heikki Henttonen ${ }^{2}$ and \\ Alexander Plyusnin ${ }^{*}, 1$
}

\author{
${ }^{I}$ Department of Virology, Haartman Institute, University of Helsinki, Finland \\ ${ }^{2}$ Finnish Forest Research Institute, Vantaa research Unit, Finland \\ ${ }^{\S}$ Current Address: Division of Veterinary Anatomy Department of Basic Veterinary Medicine P.O. Box 66, 00014 \\ University of Helsinki, Finland
}

\begin{abstract}
Genomic sequences of Tula (TULV) hantavirus were recovered from tissue samples of European common voles Microtus arvalis (subspecies obscurus) captured in Kazakhstan, Central Asia. Phylogenetic analysis of the S genomic segment of Kazakh TULV strains showed that they form distinct, well supported genetic lineage and share a more ancient common ancestor with two Russian lineages of TULV. The deduced sequence of the nucleocapsid (N) protein of Kazakh TULV strains carried specific amino acid signature: T274Q276T281. The Microtus arvalis group includes several sibling species and/or subspecies in Eurasia, indicating recent and ongoing evolutionary radiation. Our data on TULV lineages in Central Asia, the region not studied for hantaviruses earlier, highlight the diversity of both Microtus host and the virus and also their co-evolution.
\end{abstract}

\section{INTRODUCTION}

Hantaviruses (genus Hantavirus, family Bunyaviridae are negative-strand RNA viruses with a tripartite genome [1]. Currently the genus consists of at least 22 distinct hantavirus species, each thought to be carried by a specific or closely related rodent or insectivore host. Some hantaviruses, e. g. Hantaan and Sin Nombre viruses, are severe human pathogens, while others, e. g. Tula virus (TULV), are apathogenic [2]. TULV was discovered in early 1990s, first as a sequence recovered from a tissue sample of European common vole, Microtus arvalis [3]. Later it has been isolated in cell culture [4], characterized, both genetically and antigenically [5-7] and since then used as a safe model to study hantavirus molecular organization and replication [7-11], hantavirus-host interactions [7, 11-19] as well as hantavirus genetics and evolution [20-23].

After its initial discovery in Central Russia (Tula region, approxinmately $100 \mathrm{~km}$ south of Moskow [3]), TULV was reported from several European countries: Czech Republic [5, 20], Slovakia [22], Austria [24], Belgium [25], Serbia [26], Croatia [27]; Germany [28], Poland [29], France and Switzerland [23]. There are also unpublished data (four S segment sequences deposited to the GenBank) on TULV from Omsk (West Siberia); so far, this has been the only example of TULV outside Europe. Here we present our findings on TULV in Eastern Kazakhstan, Central Asia, the region not studied for hantaviruses earlier.

\footnotetext{
*Address correspondence to this author at the Department of Virology, Haartman Institute, University of Helsinki, P.O. Box 21 (Haartmaninkatu 3), FI-00014 Finland; Tel: +358-9-19126486; Fax: +358 9-19126491; E-mail: alexander.plyusnin@helsinki.fi
}

\section{MATERIALS AND METHODOLOGY}

\section{Rodent Tissue Samples}

The Microtus arvalis group is taxonomically a difficult one, and the names and species status of taxa have often changed. Here we follow Wilson and Reeder, 2005 [30]. When necessary, we also give the formerly used scientific names. Altogether, 168 Microtus voles were trapped in four main regions in Eastern Kazakhstan between April 15 and May 3, 2003. These included $128 \mathrm{M}$. arvalis obscurus, $38 \mathrm{M}$. socialis, and two $M$. oeconomus. The trapping was done in surroundings of the cities Taldykorgan and Bakanas, on foothills up to the altitude $1200 \mathrm{~m}$ of Dzungarian Mountain range east of Taldykorgan, and close surroundings of Karatal plague field station. The details of trappings, study sites, rodent species and numbers captured, etc, are given in Henttonen et al. (in preparation). Briefly, animals captured with snap traps overnight were placed in a cold box, transferred to the laboratory and kept cold until dissected in the same day. Tissue samples from lung, kidney and spleen were fixed in RNAlater reagent (Ambion, Applied Biosystems) During the trapping time nights were still cold, even frosty, and rodents were in good shape when dissected. The RNAlater-fixed lung tissue samples were screened by immunoblotting for the presence of hantaviral nucleocapsid $(\mathrm{N})$ protein antigen $(\mathrm{Ag})$ as described before [20]. Briefly, the lung tissue samples (approximately $100 \mathrm{mg}$ ) were homogenized by sonication in $500 \mathrm{mkl}$ of Laemmli sample buffer. Aliquots of $10 \mu \mathrm{l}$ were separated by electrophoresis in $10 \%$ sodium dodecyl sulphate-polyacrylamide gel and then blotted with rabbit polyclonal antibody raised against recombinant Puumala hantavirus $\mathrm{N}$ protein. Swine anti-rabbit antibodies conjugated with the horse radish peroxidase (Dako, Glostrup, Denmark) were used as secondary antibodies. 
Reverse Transcription - Polymerase Chain Reaction (RTPCR) and Sequencing

RNA was extracted from N-Ag-positive lung tissue samples using the TriPure RNA isolation system (Behringer Maannheim) following the manufacturer's instructions. PCRamplicon corresponding to complete TULV S segment sequence was prepared as described earlier [3]. This product was cloned using pGEM-Teasy cloning system (Promega, Madison, WI) and sequenced automatically using the ABI PRISM $^{\text {TM }}$ Dye Terminator or M13F and M13R Dye Primer sequencing kits (Perkin Elmer/ABI, NJ). Partial TULV S segment sequences were obtained by RT-nested PCRs. PCRamplicons were gel-purified using QIAquick Gel Extraction kit (QIAGEN) and sequenced automatically using ABI PRISM $^{\text {TM }}$ Dye Terminator sequencing kit.

\section{Phylogenetic Analysis}

Multiple nucleotide alignments were prepared manually using the SeqApp 1.9a169 sequence-editing program. Phylogenetic analysis was performed using the PHYLIP program package [31] and TreePUZZLE [32]. In PHYLIP, 500 bootstrap replicates (SEQBOOT program) were fed to the distance matrice algorithm (DNADIST, with the ML model for nucleotide substitutions), distance matrices were analyzed with the Neighbor-joining (NJ, NEIGHBOR) or FitchMargoliash (FM, FITCH) tree-fitting algorithm; the bootstrap support values were calculated with the CONSENSE program. In TreePUZZLE, the Hasegawa-Kishino-Yano-85 model was used with 10,000 puzzling steps; base frequencies were estimated from the datasets. Hantavirus sequences used for comparison were recovered from the GenBank.

\section{RESULTS}

\section{Trapping of Rodents and Screening of Rodent Tissue Samples}

In the connection of a joint European Union supported research project on plague dynamics [33], also the material on rodent-borne viruses was collected in eastern Kazakhstan in spring 2003. Details of trapping and general results of screening for several rodent-borne viruses will be published elsewhere (Henttonen et al., in preparation). One hundred twenty eight Microtus arvalis voles were first screened by immunoblotting for the presence of hantaviral $\mathrm{N}-\mathrm{Ag}$ and 20 were found positive. Of those, 15 were from the surroundings of Taldykorgan, 1 from foothills of Dzungarian Range, and 4 from Karatal. In addition we had 38 Microtus socialis voles, 2 of which were weakly $\mathrm{N}-\mathrm{Ag}$-positive. Two $M$. oeconomus were N-Ag-negative. Next, the N-Ag-posive samples were analyzed using RT-PCR and hantaviral genomic sequences ( $\mathrm{S}$ segment) were recovered from four of them (all four were M. arvalis obscurus).

\section{Genetic Characterization of Hantaviral Sequences}

Since the PCR-amplicon corresponding to complete viral $\mathrm{S}$ segment sequence (1830 nucleotides, nt) was successfully obtained from only one sample (\#322 from Karatal), a variety of RT-nested PCRs was used to recover partial S segment sequences from other three samples (experimental details are available upon request). Lower-than-usual efficiency of RT-PCR in detecting TULV sequences among the N-Ag- positive samples could be due to suboptimal conditions of field samples transportation and storage. All recovered hantaviral sequences belonged to TULV genotype. Corresponding wild-type TULV strains were designated as following: TUL/Karatal/Ma322/2003, TUL/Karatal/Ma340/2003, TUL/ Taldykorgan/Ma343/2003 and TUL/Taldykorgan/Ma216/ 2003, or Karatal322, Karatal340, Taldykorgan343, and Taldykorgan216, for short. For strains Karatal340 and Taldykorgan343, nt 142 to 1296 or nt 142 to 1206 of the S segment sequence were recovered, respectively. The shortest sequence, nt 909 to 1206, was recovered for strain Taldykorgan216. The S segment sequences of four Kazakh wt-TULV strains showed diversity between $1.6 \%$ and $2.4 \%$. Notably, all observed nt substitutions appeared to be silent thus the deduced amino acid (aa) sequences of the $\mathrm{N}$ protein were identical in all four TULV strains. This suggested a strong negative (stabilizing) selection operating at the $\mathrm{N}$ protein level.

Complete S segment sequence of Karatal322 strain was $1830 \mathrm{nt}$ long (the first and the last 22 nucleotides of the amplicon originated from the PCR primer and thus were not determined directly). The sequence included: the 5'noncoding region (NCR, nt 1 to 42), the open reading frame for the 430 aa-long N protein (nt 43 to 1335) and the $3^{\prime}-\mathrm{NCR}$ (nt 1336 to 1830). The sequence showed the highest level of identity (87\%) to TULV strains from Russia (Tula) and East Slovakia (Kosice). Other TULV strains from Slovakia (Malacky) and Russia (Omsk) and also strains from Chech Republic, Germany, Serbia, Croatia and Poland were more distantly related: sequence identities $84-86 \%$. Similarly, the deduced aa sequence of the $\mathrm{N}$ protein from Karatal322 strain was most closely related to the $\mathrm{N}$-sequences of Tula and Kosice strains: sequence diversity was as low as $1.9-2.8 \%$. The $\mathrm{N}$ protein sequences of other TULV strains showed higher diversities: $3.0-4.7 \%$. Kazakh $\mathrm{N}$ protein sequence carried specific aa signature, T274Q276T281, usually an indicator of a distinct lineage.

On phylogenetic tree calculated for the S segment sequences, TULV strains from Kazakhstan formed distinct, well-supported genetic lineage indeed (Fig. (1); FM- and PUZZLE- trees revealed same branching pattern, not shown). Within the lineage, TULV strains show geographic clustering: two strains from Karatal were located close to each other. The monophily of these two strains was apparent on the NJ- and FM-trees and received reasonably high bootstrap support: $65 \%$ and $63 \%$, respectively. Five other lineages of TULV were seen on the phylogenetic tree (Fig. 1). Two Russian lineages included strains from Tula (Central Russia) and Omsk (West Siberia), respectively. The fourth lineage consisted of strains from Germany and Poland, the fifth lineage of strains from East Slovakia and Serbia, and the sixth - from Croatia and Central Europe (Germany, Switzerland, West Slovakia, and Czech Republic). Interestingly, the Kazakh lineage shared a more ancient common ancestor with two Russian lineages. Similarly, the fifth and the sixth lineages shared a common ancestor and, most likely, another, even more ancient common ancestor with the fourth lineage. The bootstrap support for the monophyly of these three lineages was 68\%, for the NJ ree (Fig. 1), 63\%, for the FM-tree (not shown), and 60\%, for the PUZZLE-tree (not shown). 


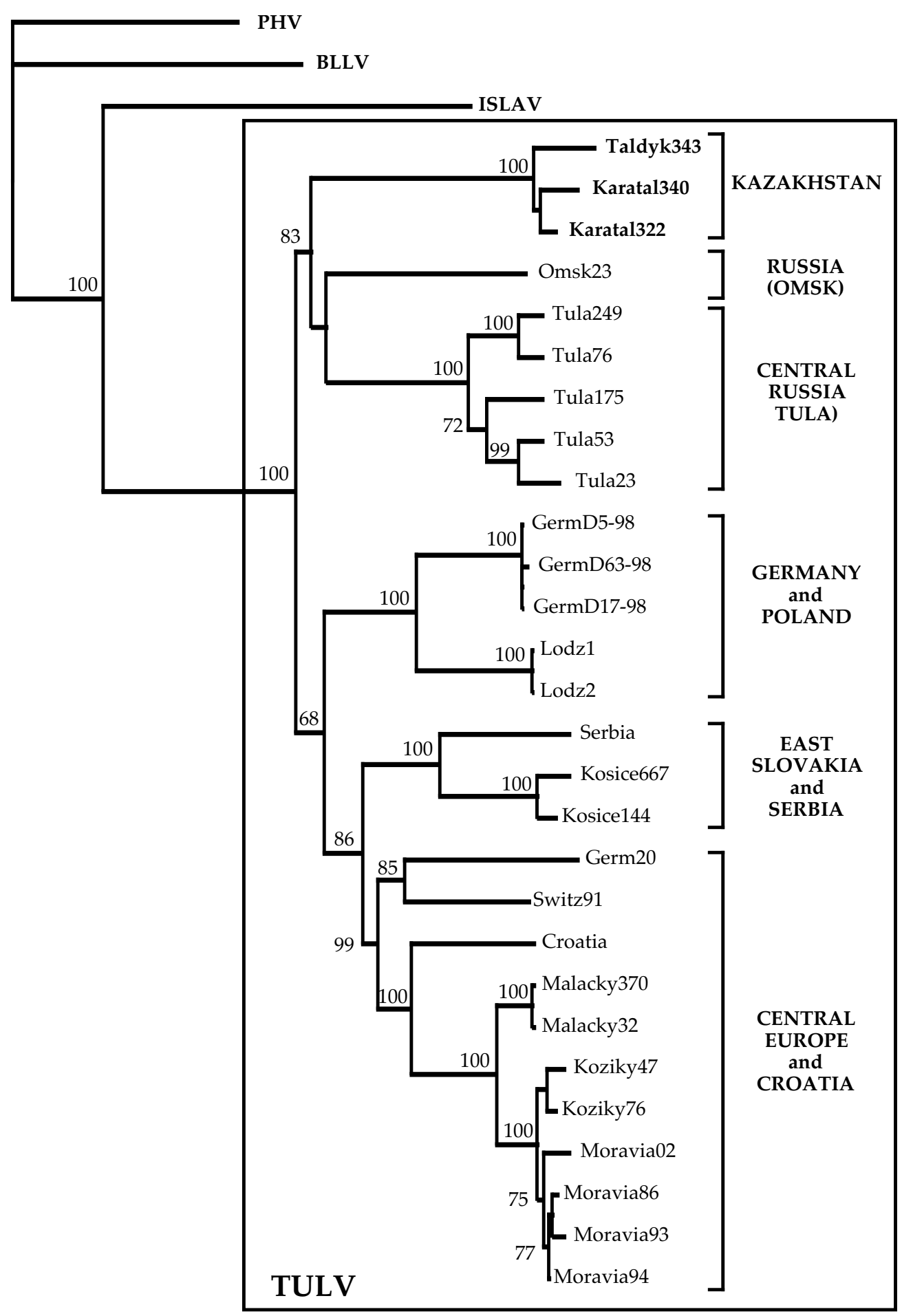

Fig. (1). Phylogenetic tree (Neighbor-joining) of TULV based on the coding region of the S segment (nt 141-1206). Only bootstrap support values greater than 70\% are shown. PHV, Prospect Hill virus, strain PH-1 (GenBank accession number Z49098); BLLV, Bloodland Lake virus, strain MO46 (U19303); ISLAV, Isla Vista virus, strain MC-SB-47 (U19302). Tula virus (TULV) strains: Taldyk343, Taldykorgan/Ma343/2003 (AM945879); Karatal340, Karatal/Ma340/2003 (AM945878); Karatal322, Karatal/Ma322/2003 (AM945877); Omsk23, MG23/Omsk (AF442621); Tula 249, Tula/249Mr/87 (Z30944); Tula76, Tula/76Ma/87 (Z30941); Tula175, Tula/175Ma/87 (Z30943); Tula53, Tula/53Ma/87 (Z30942); Tula23, Tula/23Ma/87 (Z30945); GermD5-98, Germany/D5-98 (AF289819); GermD63-98, Germany/D63-98 (AF289821); GermD17-98, Germany/D17-98 (AF289820); Lodz1 (AF063892); Lodz2 (AF063897); Serbia (AF017659); Kosice667, Kosice/667Ma/95 (Y13980); Kosice144, Kosice/144Ma/95 (Y13979); Germ20, Germany/g20-s (AF164093); Switz91, Switzerland/91Ma; Croatia, Croatia/c109-s (AF164094); Malacky370, Malacky/370Ma/94 (U31534); Malacky32, Malacky/32Ma/94 (Z48234); Koziky47, Koziky/5247Ma/94 (AJ223600); Koziky76, Koziky/5276Ma/94 (AJ223601); Moravia02, Moravia/5302Ma/94 (Z49915); Moravia86, Moravia/5286Ma/94 (Z48573); Moravia93, Moravia/5293Ma/94 (Z48574); Moravia94, Moravia/5294Ma/94 (Z48741). 
With three exceptions, namely: (1) strain Tula249 from M. levis (former rossiaemeridionalis or epiroticus), a sibling species to M. arvalis, (2) strain Serbia from M. subterraneus (former Pitymus subterraneus), and (3) strain Omsk23 from M. gregalis, TULV strains presented on Fig. (1) originate from $M$. arvalis. The first strain belongs to Central Russian lineage and shows minimal genetic diversity from $M$. arvalis- carried strains that circulated within the same locality [3]. The second strain [26] is closely related to Kosice TULV strains from East Slovakia [22], with which it forms the fifth genetic lineage. Omsk23 strain presents a distinct lineage, but certainly belongs to TULV genotype.

\section{DISCUSSION}

Data presented in this paper describe the first TULV strains from Central Asia. Kazakh strains from two localities, Taldykorgan and Karatal, constitute novel, distinct genetic lineage of TULV. This lineage is well-supported on phylogenetic trees and possesses a unique aa signature: T274Q276T281. Kazakh TULV lineage appears to be most closely related to lineages from Central Russia and Siberia. These three lineages share a common ancestor (bootstrap support value $83 \%$, on the NJ-tree) and also several signature aa residues. Kazakh and Central Russian lineage share three signature aa residues: N42, E60, and I269, while Kazakh and Siberian lineage share one signature aa residue D291. These observations suggest common evolution history for Kazakh, Central Russian and Siberian lineages of TULV, which is somewhat different from the history of other three lineages that include strains from Central Europe (Germany, Switzerland, Slovakia, and Czech Republic), Poland and the Balkans and share another common ancestor. It should be noted that two groups of TULV lineages were seen in the recently published phylogeny based on partial S segment sequences [23] (except that Kazakh lineage was not present). The current phylogeny, based on longer sequences (almost complete coding region of the S segment), is more robust: most of the bootstrap support values are above the widely accepted confidential limit of 70\% [34] - and hence more convincing.

Grouping of TULV lineages might had been rooted to glacial distribution patterns of Microtus voles across Europe and Central Asia. The ice age evolution of European small rodent species has been characterized by isolated refugia, not only in southern peninsulas, but also in more northern regions [35-37]. This is due to the fragmenting/isolating impact of several mountain ranges. In contrast, the last ice age and subsequent formation of vast steppe areas from Eastern Europe to Central Asia have probably supported more continuous Microtus populations.

As mentioned above, the vast majority of TULV genomic sequences available so far originate from $M$. arvalis that is considered the main natural host for the virus $[1,3]$. There are also exceptions, like the three sequences listed in the Results and also, e.g., partial S-sequences recovered from $M$. agrestis (field vole) [27] and even from Lagurus lagurus (steppe lemming) (GenBank accession numbers AF44261819). Geographical ranges of M. levis, M. subterraneus and $M$. agrestis overlap widely with the range of $M$. arvalis [38, 39 ] and therefore the virus spillover from $M$. arvalis to these species can not be excluded. However, some observations, e.g. higher infection rate in M. agrestis than in M. arvalis in Croatia, suggested, that $M$. agrestis in some areas can serve as another natural host for TULV [27]. As for M. gregalis, its range overlaps only with the easternmost parts of $M$ arvalis range in western-central Siberia [39] and the spillover of TULV from $M$ arvalis to $M$. gregalis is less likely. It thus seems that Tula can infect a number of Microtus species, even those in different subgenera [for subgenera, see 35]: $M$. arvalis and sibling species in Microtus group, M. agrestis in Agricola group, M. subterraneus in Terricola group, and even M. gregalis in Stenocrarius group that phylogenetically is most distant from the arvalis group [35]. In connection to this, it might be of interest that the carrier of Kazakh TULV strains, M. arvalis obscurus, currently classified as one of the chromosome forms in M. arvalis [30], has sometimes been considered a parapatric species of its own [38]. But, even if TULV proven to have two or more rodent host species, this would not be an exception. For instance, Sin Nombre hantavirus in some areas is harboured by deer mouse Peromyscus maniculatus and in others by white-footed mouse P. leucopus [40].

Microtus radiation in many taxa is an evolutionarily recent process, more recent than e.g. in Myodes (former Clethrionomys), and is still ongoing [35]. It seems that in Eurasia TULV can infect several Micotus species, also not closely related ones in different subgenera. Most importantly, TULV strains harboured by different Microtus species from the same region resemble each other. It therefore safe to assume that geographic distance was so far the major factor for the diversification of TULV lineages. Our data showing that Kazakh TULV strains are most closely connected to strains from West Siberia and Central Russia, be their host in the same or different subgenus of Microtus, support this point of view. Unusually high host diversity of TULV could be seen as an indication of young stage of its rodent host radiations and the virus-host co-evolution (the radiation of Microtus began 2 million years ago, but many of the sibling species have developed during the last $100000-200000$ years).

\section{CONCLUSIONS}

Our results demonstrate the presence of TULV in common vole $M$. arvalis in Kazakhstan. Kazakh TULV strains form a distinct genetic lineage and share a more ancient common ancestor with TULV strains currently circulating in Central Russia (Tula region) and West Siberia (Omsk region). The Microtus arvalis group includes several sister species and/or subspecies in Eurasia, indicating recent and ongoing evolutionary radiation. Our data on TULV lineages in Central Asia, the region not studied for hantaviruses earlier, highlight the diversity of Microtus host and the virus and their co-evolution.

\section{ACKNOWLEDGEMENTS}

This work was supported by grants from The Academy of Finland, Sigrid Jusélius foundation (Finland) and EU grant ICA2-CT-2000-10048. TULV genome sequences described in this paper have been deposited to the GenBank under acc. numbers AM945877-79. 


\section{REFERENCES}

[1] Nichol ST, Beaty BJ, Elliott RM, Goldbach R, Plyusnin, A, Schmaljohn CS, Tesh RB. Bunyaviridae. In: Fauquet CM, Mayo MA, Maniloff J, Desselberger U, Ball LA, Eds. Virus taxonomy. VIIIth report of the International Committee on Taxonomy of Viruses. Amsterdam, Elsevier Academic Press 2005; 695-716.

[2] Vapalahti O, Mustonen J, Lundkvist Å, Henttonen H, Plyusnin A, Vaheri A. Hantavirus infections in Europe (Review). Lancet Infect Dis 2003; 3: 653-661.

[3] Plyusnin A, Vapalahti O, Lankinen H, et al. Tula virus: a newly detected hantavirus carried by European common voles. J Virol 1994; 68: 7833-7839.

[4] Vapalahti O, Lundkvist $\AA$, Kukkonen SKJ, et al. Isolation and characterization of Tula virus: a distinct serotype in genus Hantavirus, family Bunyaviridae. J Gen Virol 1996; 77:3063-3067

[5] Plyusnin A, Cheng Y, Lehväslaiho H, Vaheri A. Unique and conserved features of Tula hantavirus $M$ gene encoding envelope glycoproteins G1 and G2. Virus Genes 1996; 12: 259-266.

[6] Lundkvist Å, Vapalahti O, Plyusnin A, Brus Sjölander K, Niklasson B, Vaheri A. Characterization of Tula hantavirus antigenic determinants defined by monoclonal antibodies raised against baculovirus-expressed nucleocapsidprotein. Virus Res 1996; 45: 29-44.

[7] Kukkonen SKJ, Vapalahti O, Vaheri A, Plyusnin A. Completion of the sequencing of the genome of Tula hantavirus. Heterogeneity found in the 3' ends of S and L genome RNAs. J Gen Virol 1998; 79: 2615-2622.

[8] Kukkonen SKJ, Vaheri A, Plyusnin A. Tula hantavirus L protein is a $250 \mathrm{kDa}$ perinuclear membrane-associated protein. J Gen Virol 2004; 85: 1181-1189.

[9] Kaukinen P, Kumar V, Tulimäki K, Engelhardt P, Vaheri A, Plyusnin A. Oligomerization of hantavirus $\mathrm{N}$ protein: interactions of C-terminal alpha-helices by sharing a hydrophobic space. J Virol 2004; 78: 13669-13677.

[10] Alminaite A, Halttunen V, Kumar V, Vaheri A, Holm L, Plyusnin A. Oligomerization of hantavirus nucleocapsid protein: analysis of the N-terminal coiled-coil domains J Virol 2006; 80: 9073-9081.

[11] Jääskeläinen K, Kaukinen P, Minskaya ES, et al. Tula and Puumala hantavirus NSs ORFs are functional and the products inhibit activation of the interferon-beta promoter. J Med Virol 2007; 79: 15271536.

[12] Kanerva M, Melen K, Vaheri A, Julkunen I. Inhibition of Puumala and Tula hantaviruses in Vero cells by MxA protein. Virology 1996; 224:55-62.

[13] Gavrilovskaya IN, Peresleni T, Geimonen E, Mackow ER. Pathogenic hantaviruses selectively inhibit beta3 integrin directed endothelial cell migration. Arch Virol 2002; 147: 1913-1931.

[14] Kaukinen P, Vaheri A, Plyusnin, A. Non-covalent interaction between nucleocapsid protein of Tula hantavirus and small ubiquitinrelated modifier-1, SUMO-1. Virus Res 2003; 92: 37-45.

[15] Kraus AA, Raftery MJ, Giese T, et al. Differential antiviral response of endothelial cells after infection with pathogenic and nonpathogenic hantaviruses. J Virol 2004; 78: 6143-6150.

[16] Li X, Kukkonen SKJ, Vapalahti O, Plyusnin A, Lankinen H, Vaheri A. Tula hantavirus infection of Vero E6 cells induces apoptosis involving caspase 8 activation. J Gen Virol 2004; 85: 3261 3268.

[17] Hardestam J, Klingström J, Mattsson K, Lundkvist A. HFRS causing hantaviruses do not induce apoptosis in confluent Vero E6 and A-549 cells. J Med Virol 2005; 76: 234-240.

[18] Cebalo L, Marcotic A. Chemokine production predominates in human monocytes infected with Tula virus. Viral Immunol 2007; 20:206-213

[19] Jääskeläinen KM, Plyusnina A, Lundkvist Å, Vaheri A, Plyusnin A. Tula hantavirus isolate with the full-length ORF for nonstructural protein NSs survives in interferon-competent cells for more consequtive passages than the isolate having truncated NSs ORF. Virol J 2008; $5: 3$.

[20] Plyusnin A, Cheng Y, Vapalahti O, et al. Genetic variation in Tula hantaviruses: sequence analysis of the $\mathrm{S}$ and $\mathrm{M}$ segments of strains from Central Europe. Virus Res 1995; 39: 237-250.

[21] Plyusnin A, Cheng Y, Vapalahti O, Lehväslaiho H, Vaheri A. Quasispecies in wild Tula hantavirus populations. J Virol 1996; 70 9060-9063.

[22] Sibold C, Meisel H, Krüger DH, et al. Recombination in Tula hantavirus evolution: analysis of genetic lineages from Slovakia. J Virol 1999; 73: 667-675.

[23] Plyusnina A, Deter J, Charbonnel N, Cosson J-F, Plyusnin A. Puumala and Tula hantaviruses in France. Virus Res 2007; 129:5863.

[24] Bowen MD, Gelbmann W, Ksiazek TG, Nichol ST, Nowotny N. Puumala virus and two genetic variants of Tula virus are present in Austrian rodents. J Med Virol 1997; 53: 174-181.

[25] Heyman P, Klingström J, De Jaghere F, et al. Tula hantavirus in Belgium. Epidemiol Infect 2002; 128: 251-256.

[26] Song JW, Gligic A, Yanagihara R. Identification of Tula hantavirus in Pitymys subterraneus captured in the Cacak region of SerbiaYugoslavia. Int J Infect Dis 2002; 6: 31-36.

[27] Scharninghausen JJ, Pfeffer M, Meyer H, Davis DS, Honeycutt RL, Faulde M. Genetic evidence for tula virus in Microtus arvalis and Microtus agrestis populations in Croatia. Vector Borne Zoonotic Dis 2002; 2: 19-27.

[28] Klempa B, Meisel H, Räth S, Bartel J, Ulrich R, Krüger DH. Occurrence of renal and pulmonary syndrome in a region of northeast Germany where Tula hantavirus circulates. J Clin Microbiol.2003, 41: 4894-4897.

[29] Song JW, Baek LJ, Song KJ, et al. Characterization of Tula virus from common voles (Microtus arvalis) in Poland: evidence for geographic-specific phylogenetic clustering. Virus Genes 2004; 29: 239-47.

[30] Wilson DE, Reeder DA. Mammal species of the world. A taxonomic and geographic reference. John Hopkins Univ, Baltimore; 2005.

[31] Felsenstein J. PHYLIP [Phylogeny Inference Package], 1993; 3.5c

[32] Schmidt HA, Strimmer K, Vingron M, von Haesseler A. TREEPUZZLE: maximum likelihood phylogenetic analysis using quartets and parallel computing. Bioinformatics 2002; 18: 502-504.

[33] Davis S, Begon M, De Bruyn L, Ageyev VS. Predictive thresholds for plague in Kazakhstan. Science 2004; 304: 736-738.

[34] Hillis DM, Bull JJ. An empirical test of bootstrapping as a method for assessing confidence in phylogenetic analysis. Syst Biol 1993 42: 182-192.

[35] Jaarola M, Martínková N, Gündüz X, et al. Molecular phylogeny of the speciose vole genus Microtus (Arvicolinae, Rodentia) inferred from mitochondrial DNA sequences. Mol Phyl. Evol 2004; 33: 647-663.

[36] Kotlik P, Deffontaine V, Mascheretti S, Zima J, Michaux JR, Searle JB. A northern glacial refugium for bank voles (Clethrionomys glareolus). - PNAS 2006; 103: 14860-14864.

[37] Deffontaine V. Histoire évolutive du campagnol roussâtre (Myodes (Clethrionomys) glareolus) en Eurasia. PhD Thesis, 189pp. Univ. Liege; 2008.

[38] Mitchell-Jones AG, Amori G, Bogdanowicz W, Krystufek B, Reijnders PJH, Spitzenberger F, Stubble M, Thissen JBM, Vohralik V, Zima J. The Atlas of European Mammals, pp. 484. London: T \& AD Poyser Natural History; 1999.

[39] Shenbrot GI, Krasnov BR. An atlas of the geographic distribution of the arvicoline rodents of the world (Rodentia; Mudidae: Arvicolinae). Pennsoft Publisher, Sofia; 2005.

[40] Morzunov SP, Rowe JE, Monroe MC, et al. Genetic analysis of the diversity and origin of hantaviruses in Peromyscus leucopus mice in North America. J Virol 1998; 72: 57-64. 